\title{
РАЗВИТИЕ ИССЛЕДОВАНИЙ ПО РЕПРОДУКТИВНОЙ ПСИХОЛОГИИ НА КАФЕДРЕ ОБЩЕЙ ПСИХОЛОГИИ И ИСТОРИИ ПСИХОЛОГИИ МОСКОВСКОГО ГУМАНИТАРНОГО УНИВЕРСИТЕТА
}

\author{
Г. Г. Филиппова \\ Московский гуманитарный университет
}

\begin{abstract}
Аннотация: В статье описано формирование и современное состояние оригинального направления научных исследований, проводимое на кафедре под руководством Г. Г. Филипповой - репродуктивная психология. Развитие этого направления связано с актуальными запросами науки и практики в области нарушений раннего развития ребенка, детско-родительских отношений, психологической неготовности к родительству, нарушений репродуктивного здоровья женщин и мужчин и использования вспомогательных репродуктивных технологий.
\end{abstract}

Ключевые сова: научная школа, перинатальная психология, репродуктивная психология, репродуктивная сфера, нарушения репродуктивного здоровья; кафедра общей психологии и истории психологии; Московский гуманитарный университет

\section{THE DEVELOPMENT OF THE RESEARCH INTO REPRODUCTIVE PSYCHOLOGY AT THE DEPARTMENT OF GENERAL PSYCHOLOGY AND THE HISTORY OF PSYCHOLOGY OF MOSCOW UNIVERSITY FOR THE HUMANITIES}

\author{
G. G. Filippova \\ Moscow University for the Humanities
}

\begin{abstract}
The paper describes the formation and contemporary state of a unique research discipline - reproductive psychology. The study is being conducted at the department under the supervision of G. G. Fillipova. The development of this discipline is connected with the acute demands of the science and practice in the area of children's early development disorders, parentchild relationships, psychological unpreparedness to parenthood, reproductive health problems of women and men, and the use of assisted reproductive technologies.

Keywords: school of thought; perinatal psychology; reproductive psychology; reproductive area; reproductive health problems; Department of General Psychology and the History of Psychology; Moscow University for the Humanities
\end{abstract}

Исследования по репродуктивной психологии начали проводиться на кафедре в 90-е годы XX века в рамках перинатальной психологии и психологии материнства (Филиппова, 1999). За это время был пройден большой путь от изучения психологических особенностей беременности и ранних отношений матери с ребенком до исследования психологических механизмов регуляции репродуктивной функции у женщин и мужчин, психологических факторов нарушений репродуктивного здоро- 
вья и практических разработок по психологической помощи семье на всех этапах репродуктивного цикла (Филиппова, 2015а; 2018).

В основе направления лежали исследования, задуманные и реализованные Г. Г. Филипповой и ее учениками в области нескольких проблемных областей отечественной психологии: психологии раннего развития, психологии родительства (материнства и отцовства), психологии детско-родительских отношений, психологии беременности. В психологической практике основанием для такого объединения стал опыт ведения курсов для будущих родителей по подготовке к родам и родительству, консультирование детско-родительских отношений, тренинги для родителей и др. На определенном этапе разработки, все эти научные и практические направления, достаточно близкие и тесно между собой связанные, объединились в единое направление исследований, которое получило название «перинатальная психология».

В последнее десятилетие в развитии этого направления произошел ряд изменений, связанных как с развитием самой науки, так и с изменением запросов практики. Эти изменения в первую очередь связаны с тем, что в начале нашего столетия во всем мире и в России, в том числе, началась эпоха демографических проблем, проявлением которых стало нарастающее нарушение репродуктивного здоровья населения. Как результат - появился запрос на психологическую помощь при нарушениях течения беременности, бесплодии и невынашивании беременности, а несколько позже и при нарушениях репродуктивной функции у мужчин. Активное развитие вспомогательных репродуктивных технологий в медицине также способствовало обращению к вопросам нарушений репродуктивного здоровья и к возможности оказания психологической помощи пациентам репродуктивных клиник. Развитие теоретических подходов в перинатальной психологии, психологии родительства и других смежных областях психологии позволило выделить и обосновать новый предмет науки и практики - психологию репродуктивной сферы человека (Филиппова, 2015a). Теоретической основой этого подхода является теория функциональных систем и учение о доминанте, в сочетании с классическими и современными подходами в психоанализе и перинатальной психологии. С опорой на учение о функциональных системах П. К. Анохина и доминанте А. А. Ухтомского репродуктивная функция человека рассматривается как сложная функциональная система, при этом описано системное строение репродуктивной сферы и выделены этапы репродуктивного цикла. Репродуктивная сфера определяется нами как организация всех систем жизнедеятельности человека для осуществления репродуктивной функции. В репродуктивной сфере выделяются психологическая и физиологическая составляющие, обосновывается их взаимосвязь. В этом подходе, с опорой на результаты конкретно-эмпирических исследований, физиологические нарушения репродуктивного здоровья рассматриваются как психосоматическое проявление нарушений в репродуктивной сфере женщин и мужчин. Сформулированы положения репродуктивной психосоматики, обоснованы ее специфические особенности и отличия от психосоматических соотношений в других сферах жизнедеятельности (Филиппова, 2015b).

Поиск причин нарушений в реализации репродуктивной функции позволил разработать представление о психологической неготовности к родительству и ее 
связи с проблемами в ранних детско-родительских отношениях. Сравнение психологических особенностей женщин с диагнозом «бесплодие», «невынашивание беременности», женщин, оттягивающих рождение детей до позднего репродуктивного возраста, а также тех, кто сознательно отказывается от рождения детей, выявило сходство в их психологической неготовности к родительству. Это положение находит свое подтверждение при изучении нарушений раннего развития ребенка, которое в ряде случаев также связано с разными формами искажений детско-родительских отношений (Филиппова, 2015c). Эти искажения возникают в результате психологической неготовности родителей к рождению и воспитанию детей. Таким образом, была обоснована теоретическая и практическая связь проблематики перинатальной психологии и психологии репродуктивной сферы. Еще одним достижением этого периода стало понимание психосоматической природы нарушений репродуктивного здоровья как женщин, так и мужчин, что привело к появлению термина «репродуктивная психосоматика» (Филиппова, 2015b).

Эти явления в современной науке и практике послужили основанием для нового этапа интеграции всех направлений, которые занимаются разными аспектами рождения и развития человека с одной стороны - и тем, как это рождение и развитие обеспечивается женщинами и мужчинами, родителями ребенка - с другой стороны. Сформировалась устойчивая связь нескольких областей психологии и смежных наук, ориентированных на проблемы воспроизводства - рождения и воспитания детей, и репродуктивной функции женщин и мужчин - как способности к рождению и воспитанию детей. Это три основных области, тесно пересекающиеся между собой: перинатальная психология, объединяющая в себе вопросы раннего развития ребенка и родительского (материнского и отцовского) отношения и поведения; психология родительства, изучающая материнство и отцовство как часть личностной сферы взрослого человека; психология репродуктивной сферы, охватывающая психологические и психосоматические вопросы реализации репродуктивной функции.

В результате пересечения означенных проблем в современной психологии появилось новое направление - репродуктивная психология, в которую включены все психологические аспекты репродуктивного здоровья. В этом направлении выделяется две взаимосвязанные составляющие репродуктивного здоровья: физиологическая - как способность зачать, выносить и родить здорового ребенка, и психологическая - как способность вырастить и воспитать здорового физически и психически ребенка и подготовить его к реализации репродуктивной функции в будущем. При таком подходе репродуктивная функция рассматривается как рождение и воспитание детей, которые сами смогут продолжить род - то есть смогут сами родить и воспитать здоровое потомство.

В результате такой интеграции произошло логичное объединение тех направлений психологии, которые, с одной стороны занимались разными этапами реализации репродуктивной функции (то есть разными этапами репродуктивного цикла - от онтогенеза репродуктивной функции до ее реализации у взрослых женщин и мужчин), а с другой стороны - разными психологическими аспектами репродуктивной функции (психофизиологическими, ценностно-смысловыми, гендерными, поведенческими, психосоматическими и т. п.). 
В проведенных в этом направлении исследованиях и практическом опыте работы психологов с разными аспектами репродуктивной функции семьи было выявлено, что существует непосредственная связь психологических и психосоматических проблем, возникающих на различных этапах репродуктивного цикла, с проблемами раннего развития и детско-родительских отношений. В таком аспекте логика развития направления от перинатальной к репродуктивной психологии отражает общую логику взаимосвязи раннего развития со всей последующей жизнью человека. Более того, она отражает связь между проблемами прошлых и будущих поколений как циклической трансляции закономерностей от рождения до рождения. Действительно, перинатальная психология, занимающаяся проблемами раннего развития человека, оказывается своеобразным ядром, в котором заложены ростки и векторы всех остальных направлений репродуктивной психологии. Однако, расширяя свои границы, она порождает и более широкие круг междисциплинарных проблем в области науки и практики, новые теоретические подходы и методы работы, которые уже не укладываются в ее узкие границы. Поэтому сама она остается с одной стороны центральной, а с другой стороны составной частью своего «порождения» - репродуктивной психологии, которая занимается всеми аспектами репродуктивной функции человека.

Современное состояние обозначенных направлений свидетельствует о том, что появился новый объект изучения и практического приложения в современной психологической науке - это психологические аспекты репродуктивной функции человека - в котором каждое направление выделяет свой предмет, но для полноты его понимания стремится к интеграции со смежными направлениями, также выделяющими в этом объекте свои частные предметы.

Это означает, что проблема репродукции стала общим профессиональным полем для психологов, а репродуктивный цикл - как все, что связано с воспроизводством в широком смысле - общим для этой области объектом науки и практики. В таком случае для этой области психологии общим предметом становятся психологические аспекты реализации репродуктивной функции, и каждое направление выделяет в качестве конкретно-научного предмета один из этих аспектов. Это позволяет говорить о выделении нового междисциплинарного (объединяющего разные области психологии) направления в современной психологии, пересекающегося также со смежными науками - медициной, психосоматикой, философией, педагогикой.

Таким образом, за прошедшие два десятилетия наших с коллегами исследований тематика и потенциальные направления исследований прошли ряд этапов своего развития от работы с беременными и диадой - до системного подхода к психологическим проблемам репродуктивной функции семьи. Репродуктивная психология объединяет все психологические аспекты репродуктивной функции - от общего онтогенеза, включающего онтогенез репродуктивной сферы - до реализации репродуктивной функции и нарушений физиологической и психологической составляющих репродуктивного здоровья. Это направление охватывает все этапы репродуктивного цикла, в нем объединяется проблематика перинатальной психологии, психологии материнства и отцовства, психологии репродуктивной сферы и психологии нарушений репродуктивного здоровья. В настоящее время в репродук- 
тивной психологии разработаны теоретико-методологические основы представлений о психологической составляющей репродуктивной функции человека, опирающиеся на эволюционно-системный подход, учение о функциональных системах, психосоматический подход, классические и современные теории раннего развития. В этой области уже сложился свой категориальный аппарат, ориентированный на комплексность знаний, междисциплинарные связи и применение интегративного подхода в практической психологической работе.

Одним из направлений современной репродуктивной психологии является проблематика, связанная с использование вспомогательных репродуктивных технологий. Выявлены психологические факторы возникновения психосоматических осложнений репродуктивного здоровья, дана характеристика основных типов психосоматических нарушений в репродуктивной сфере (Филиппова, 2015a). Получены новые данные о влиянии раннего онтогенеза на формирование психосоматических осложнений в репродуктивной сфере. Выявлены особенности нарушения женской идентичности, связанные с нарушением менструальной функции (Филиппова и др., 2017).

Крупным достижением практического направления описываемой проблематики является установление прочной связи репродуктивной психологии с репродуктивной медициной. Вопросы перинатальной и репродуктивной психологии постоянно обсуждаются на ведущих Российских и Международных психологических и медицинских конгрессах и конференциях, в рамках которых организуются психологические симпозиумы, а также проводятся образовательные лекции и семинары по психологическим аспектам репродуктивного здоровья для психологов, врачей акушеров-гинекологов и репродуктологов. По результатам этой работы разработан и реализован план образовательных семинаров для врачей вспомогательных репродуктивных технологий в ряде городов России: Санкт-Петербурге, Самаре, Екатеринбурге, Красноярске, Новосибирске, Краснодаре и других городах и регионах. Разработана и внедрена программа семинаров и практических тренингов по оптимизации взаимодействия врачей с пациентами и коррекции негативных эмоциональных состояний для медицинских работников акушерско-гинекологических клиник и клиник вспомогательных репродуктивных технологий.

В Московском гуманитарном университете в течение 25 лет под руководством и при непосредственном участии, доктора психологических наук, профессора Г. Г. Филипповой сложился научный коллектив, в котором совместными усилиями разрабатываются и читаются учебные курсы, проводятся научные исследования в рамках студенческих дипломных работ и диссертационных исследований аспирантов. С середины 1990-х годов читаются образовательные курсы по перинатальной и репродуктивной психологии, проводились мастер-классы со студентами, разработаны учебные программы для студентов и магистрантов: «Перинатальная психология и психология родительства», «Психологическое консультирование по вопросам репродуктивного здоровья женщин и мужчин», защищены дипломные работы студентов, получившие высокую оценку в конкурсах дипломных работ. В настоящее время на кафедре подготовлены диссертации и ведутся исследования аспирантов по формированию психологической готовности к родительству в онтогенезе (Филиппова, Абдуллина, 2017), по проблемам раннего развития ребенка, по изучению 
психологических особенностей женщин с нарушениями репродуктивного здоровья (Филиппова и др., 2017).

\section{СПИСОК ЛИТЕРАТУРЫ}

Филиппова, Г. Г. (1999). Психология материнства: концептуальная модель. М. : Институт молодежи. 286 с.

Филиппова, Г. Г. (2015а) Репродуктивная психология в России: современные проблемы и тенденции развития // Психотерапия. № 4 (148). С. 65-70.

Филиппова, Г. Г. (2015b) Репродуктивная психосоматика: специфика психосоматических соотношений в репродуктивной сфере // Психотерапия. № 11 (155). С. $40-45$.

Филиппова, Г. Г. (2015c) Пренатальный стресс: усиление риска при современных технологиях ведения беременности и лечения бесплодия // VI-ая Международная научная конференция «Психологические проблемы современной семьи: сборник тезисов» 30 сентября - 4 октября 2015 г. / под ред. Карабановой О. А. и др. М. ; Звенигород. 1387 с. С. 417-426.

Филиппова, Г. Г., Абдуллина, С. А. (2016) Особенности внутренней позиции родителя у детей младшего школьного возраста // Российский психологический журнал. Т. 13. № 3. С. 123-140.

Филиппова, Г. Г., Кузнецова, И. В., Бурчакова, М. Н., Бурчаков, Д. И., Хаджиева, Н. Х. (2017) Психогенные стресс-зависимые нарушения менструального цикла: роль негормональной коррекции // Современная гинекология. Т. 2. Медицинский алфавит. №10 (307). С. 54-61.

Филиппова, Г. Г. (2018) Психология материнства: учебное пособие для академического бакалавриата. 2-е изд., испр. и доп. М. : Издательство Юрайт. 211 с.

Дата поступления: 10.02.2018 г.

Филиппова Галина Григорьевна - доктор психологических наук, профессор, профессор кафедры общей психологии и истории психологии Московского гуманитарного университета; член Российского психологического общества (РПО), руководитель секции перинатальной психологии РПО, действительный член, преподаватель и супервизор Общероссийской профессиональной психотерапевтической лиги (ООПЛ), ученый секретарь модальности Перинатальная психотерапия и психология и психология репродуктивной сферы ОППЛ, член Российской ассоциации репродукции человека (РАРЧ). Адрес: 111395, Россия, г. Москва, ул. Юности, д. 5 . Тел.: +7 (499) 374-67-20; +7 (916) 118-53-65. Эл. адрес: filippova_galina@mail.ru

Filippova Galina Grigoryevna, Doctor of Psychology, Professor, Professor, Department of General Psychology and the History of Psychology, Moscow University for the Humanities; Member, Russian Psychological Society, Head, Section of Perinatal Psychology; Full Member, Teacher and Supervisor, All-Russian Professional Psychotherapeutic League, Academic Secretary of the Modality of Perinatal Psychotherapy and Psychology and Psychology of Reproductive Sphere; Member, Russian Association of Human Reproduction. Postal address: 5, Yunosti St., Moscow, Russian Federation, 111395. Tel.: +7 (499) 374-67-20; +7 (916) 118-53-65. E-mail: filippova_galina@mail.ru 


\section{Для цитирования:}

Филиппова Г. Г. Развитие исследований по репродуктивной психологии на кафедре общей психологии и истории психологии Московского гуманитарного университета [Электронный ресурс] // Научные труды Московского гуманитарного университета. 2018. № 1. URL: http://journals.mosgu.ru/trudy/article/view/681 (дата обращения: дд.мм. гг.). DOI: 10.17805/trudy.2018.1.6 